\title{
The association between job satisfaction and general health among employees of Golestan Hospital in Ahvaz, Iran
}

\author{
Farzad Faraji Khiavi ${ }^{1}$, Rezvan Dashti ${ }^{2}$, Nadia Zergani ${ }^{3}$
}

${ }^{1}$ Ph.D., Assistant Professor, Department of Health Services Administration, School of Health, Ahvaz Jundishapur University of Medical Sciences, Ahvaz, Iran

${ }^{2}$ M.Sc. in Rehabilitation Administration, Musculoskeletal Rehabilitation Center, School of Rehabilitation, Ahvaz Jundishapur University of Medical Sciences, Ahvaz, Iran

${ }^{3}$ B.Sc. in Health Services Administration, School of Health, Ahvaz Jundishapur University of Medical Sciences, Ahvaz, Iran

\section{Type of article: Original}

\begin{abstract}
Introduction: Job satisfaction is one of the most challenging organizational concepts, and it is the basis of management policies to increase productivity and efficiency of the organization. The general health rate may affect job satisfaction in several ways. This study aimed to determine the association between job satisfaction and general health among employees of Golestan Hospital in Ahvaz, Iran.

Methods: The study population of this cross-sectional research included 100 employees of Golestan Hospital in Ahvaz, Iran. The data collection instruments were the General Health Questionnaire (28-GHQ) and the Job Descriptive Index (JDI) questionnaire. The data were analyzed using Pearson's product-moment correlation coefficient, independent samples t-test, and ANOVA statistical tests in SPSS software.

Results: The mean general health was calculated as $26.19 \pm 11.04$, which indicated a positive psychiatric condition. Job satisfaction with a mean score of $89.67 \pm 23.3$ was deemed to be relatively dissatisfied. A medium negative and significant association was observed between job satisfaction and general health and its subscales (physical health, anxiety, social, and depression).

Conclusions: General health subscales and job satisfaction are associated. Some actions must be planned to cope with the negative factors in general health in order to increase employees' satisfaction in university educational hospitals.
\end{abstract}

Keywords: Job satisfaction, General health, Hospital staff

\section{Introduction}

Each society as a global system has some organizations within itself. All organizations should get along with other systems concordantly to achieve the system's larger aims. The clause of this concurrent is to have organizations with intransitive and enough characteristics of a healthy organization $(1,2)$. The main operators of institutes are people. They refresh the insipid frameworks of organizations and practically facilitate the work required to meet objectives (2-5). Developing technology never ignores people's roles, but it makes some main changes in their activities; for example, most physical activities have been replaced by mental activities. Therefore, assessing people's behaviors in organizations is one of the most important administrative tasks $(6,7)$. In order to improve mental health level of their personnel, organizations are interested in making the work environments pleasant from physical, mental, and welfare perspectives. Different research results have shown that organizations can make valuable findings, such as an increase in staffs' motivation, organizational support, and behavior improvement as well as a decrease in work burnout and changing with personnel who are in good general health condition (8-10). Job satisfaction is one of the important factors in influencing productivity, increasing the quantity and quality of work, providing good relations

\section{Corresponding author:}

Rezvan Dashti, Musculoskeletal Rehabilitation Center, School of Rehabilitation, Ahvaz Jundishapur University of Medical Sciences, Ahvaz, Iran. Tel: +98.6133738269, Fax:+98.6133738282, Email: rezvan.dashti@gmail.com Received: September 08, 2015, Accepted: December 23, 2015, Published: April 2016 iThenticate screening: December 12, 2015, English editing: February 27, 2016, Quality control: March 20, 2016 (C) 2016 The Authors. This is an open access article under the terms of the Creative Commons Attribution-NonCommercialNoDerivs License, which permits use and distribution in any medium, provided the original work is properly cited, the use is non-commercial and no modifications or adaptations are made. 
in the workplace, creating interest at work, and reducing stress (11). Paying attention to mental health in all areas of life, such as personal, social, and career situations is essential, and occupations and professions are among the most critical areas in which these issues must be considered (10). Job satisfaction has always been of high concern in providing medical and hospital services, because the quality of these services depends mostly on the available human resources (12). In the healthcare sector, job satisfaction is strongly associated with quality and efficiency of services, patients' satisfaction, their recovery, and the reduction of medical costs (13). So, any damage to the physical and mental health of these human resources cannot be justified for any reason, including cost containment (14). In service sector organizations, including hospitals, where major works generally are run by people, the issue of considering human resources and their management is manifested more than in organizations where most of the work is done by machines (12). Hospitals' mission is maintaining the health of society, and a particular organizational culture dominates hospitals. Job satisfaction has a great deal of significance in these organizations, and a complex range of psychological, organizational, managerial, and sociological factors affect it. The association between hospitals' staff job satisfaction and mental health is one of the less-studied relationships (14). No research has been conducted on the association of job satisfaction and general health in Ahvaz; and Golestan Hospital is a regional hospital that delivers services to the Province and nearby provinces; in addition, it has the most diverse services and the most hospital beds and staff in the Province. By pursuing the provision of better services by more satisfied employees, this research aimed to determine the association between job satisfaction and general health among the employees of Golestan Hospital in Ahvaz, Iran.

\section{Material and Methods}

\subsection{Method and sampling}

This cross-sectional study was a descriptive study. Study population included all employees of Golestan Hospital in Ahvaz Province, Iran, in 2015. One hundred respondents were the sample size, which was calculated via the Cochran sampling formula, having population size. Cluster sampling was used for the hospital units and simple random sampling for personnel selection.

\subsection{Measures}

JDI and GHQ questionnaires were used to collect data. The JDI questionnaire consisted of 39 questions and 5 subscales. The questionnaire evaluated the employers' job satisfaction, satisfaction with supervisor, satisfaction with co-workers, promotion, and payments. According to Cronbach's alpha, the reliability equaled 0.94, but it was 0.89 based on the bisection method. The GHQ questionnaire is a self- reporting questionnaire that is used to detect psychiatric disorders in general populations. The questionnaire included 28 questions. Likert scoring was used with $0,1,2$, and 3 scores. Therefore, the respondents' general health could be scored between $0-84$. Based on Cronbach's alpha, the reliability was 0.90 , and based on the bisection method it was 0.88 .

\subsection{Statistical Analysis}

Questionnaires were completed by respondents, and the data were entered into SPSS version 16. The data were distributed normally, so descriptive statistics, Pearson's product-moment correlation coefficient, one way ANOVA, and the independent t-test were used to analyze the data. Cronbach's alpha and the bisection method were used to calculate the reliability co-efficient.

\section{Results}

\subsection{Socio-demographic characteristics}

Questionnaires were completed by 100 respondents. Their demographic characteristics are provided in Table 1, which shows that the ages of about half of the respondents (43) were in the range of 31-40. The percentages of males and females in this study were approximately equal. The majority of the respondents were physicians, and the minority was security personnel.

\subsection{General Health}

Mean and standard deviation of scores for General Health and its subscales are shown in Table 2. Physical, anxiety and depression mean scores showed a positive condition, but social dysfunctions score indicated some problems. However, mean general health score indicated a positive psychiatric condition.

\subsection{Job Satisfaction}

Scores of job satisfaction and its subscales are shown in Table 3. As it is shown in the above table, a significant difference between medical and non-medical job groups was observed just in the social subscale, and no-significant 
differences were observed in the other subscales. The mean of medical group (doctor, paramedic and nurse) was significantly better than that of the non-medical personnel (housekeeping, office staff, and security) from the social compatibility perspective $(p=0.001)$. But no difference was observed between the two general groups in the other subscales of General Health.

\subsection{Association between General Health and Job Satisfaction}

Table 4 shows the correlation between general health and job satisfaction. As the table demonstrates, with 46 effect sizes, there was a negative medium association between general health and job satisfaction. All of the general health dimensions had medium association with job satisfaction, except the social dimension, which showed a small association.

Table 1. Respondents' demographic characteristics

\begin{tabular}{|l|l|l|l|}
\hline Demographic Characteristics & Categories & $\mathrm{n}$ & Cumulative Percentage \\
\hline Age & $21-30$ & 25 & 25 \\
\cline { 2 - 4 } & $31-40$ & 43 & 68 \\
\cline { 2 - 4 } & $41-50$ & 27 & 95 \\
\cline { 2 - 4 } & More than 51 & 5 & 100 \\
\hline \multirow{5}{*}{ Jender } & Male & 49 & 49 \\
\cline { 2 - 4 } & Female & 51 & 100 \\
\hline \multirow{5}{*}{ Job } & Physician & 21 & 21 \\
\cline { 2 - 4 } & Paramedic & 20 & 41 \\
\cline { 2 - 4 } & Nurse & 18 & 59 \\
\cline { 2 - 4 } & Office staff & 20 & 79 \\
\cline { 2 - 4 } & Housekeeper & 12 & 91 \\
\cline { 2 - 4 } & Security & 9 & 100 \\
\hline Total & & 100 & 100 \\
\hline
\end{tabular}

Table 2. Scores for General Health and its dimensions

\begin{tabular}{|l|l|l|l|}
\hline General Health & Mean \pm SD & Minimum & Maximum \\
\hline Physical (somatic Symptoms) & $6.25 \pm 3.56$ & 0 & 20 \\
\hline Anxiety/ insomnia & $6.23 \pm 4.58$ & 0 & 21 \\
\hline Social Dysfunction & $11.48 \pm 3.20$ & 0 & 21 \\
\hline Severe Depression & $2.24 \pm 2.92$ & 0 & 12 \\
\hline Total & $26.19 \pm 11.04$ & 0 & 63 \\
\hline
\end{tabular}

Table 3. Scores for Job Satisfaction and its subscales

\begin{tabular}{|l|l|l|l|}
\hline Job Satisfaction & Mean \pm SD & Minimum & Maximum \\
\hline Work itself & $23.93 \pm 8.16$ & 2 & 36 \\
\hline Supervision & $27.84 \pm 6.44$ & 9 & 35 \\
\hline Co-workers & $25.09 \pm 8.27$ & 0 & 36 \\
\hline Pay & $5.35 \pm 4.31$ & 0 & 18 \\
\hline promotion & $7.70 \pm 5.87$ & 0 & 18 \\
\hline Total & $89.67 \pm 23.3$ & 20 & 132 \\
\hline
\end{tabular}


Table 4. Pearson correlation between Job Satisfaction and General Health and its dimensions

\begin{tabular}{|c|c|c|c|c|c|c|c|}
\hline \multirow[t]{2}{*}{ General Health } & \multirow{2}{*}{$\begin{array}{l}\text { Statistical } \\
\text { Indicator }\end{array}$} & \multicolumn{6}{|c|}{ Job Satisfaction } \\
\hline & & $\begin{array}{l}\text { Work } \\
\text { itself }\end{array}$ & Supervision & $\begin{array}{l}\text { Co- } \\
\text { workers }\end{array}$ & Pay & Promotion & Total \\
\hline \multirow[t]{2}{*}{ Physical Dimension } & $\begin{array}{l}\text { Pearson } \\
\text { coefficient }\end{array}$ & $-0.212 *$ & $-0.371 * *$ & $-0.325 * *$ & $\begin{array}{l}- \\
0.114\end{array}$ & $-0.220^{*}$ & $\overline{-}-387 * *$ \\
\hline & $\mathrm{p}$-value & 0.034 & $<0.001$ & 0.001 & 0.261 & 0.028 & 0.001 \\
\hline \multirow[t]{2}{*}{ Anxiety Dimension } & $\begin{array}{l}\text { Pearson } \\
\text { coefficient }\end{array}$ & $-0.206^{*}$ & $-0.364 * *$ & $-0.445^{* *}$ & $\begin{array}{l}- \\
0.104\end{array}$ & $-0.298 * *$ & $-\overline{0.448^{* *}}$ \\
\hline & $\mathrm{p}$-value & 0.04 & $<0.001$ & 0.001 & 0.3 & 0.003 & $<0.001$ \\
\hline \multirow[t]{2}{*}{ Social Dimension } & $\begin{array}{l}\text { Pearson } \\
\text { coefficient }\end{array}$ & $-0.226^{*}$ & $-0.206^{*}$ & $-0.200^{*}$ & -.012 & -0.149 & $-0.245^{*}$ \\
\hline & p-value & 0.024 & 0.04 & 0.046 & 0.91 & 0.14 & 0.048 \\
\hline \multirow[t]{2}{*}{$\begin{array}{l}\text { Depression } \\
\text { Dimension }\end{array}$} & $\begin{array}{l}\text { Pearson } \\
\text { coefficient }\end{array}$ & -0.167 & -0.165 & $-0.319 * *$ & - & -0.191 & $-\overline{0.316^{* *}}$ \\
\hline & p-value & 0.097 & 0.1 & 0.001 & 0.244 & 0.057 & 0.001 \\
\hline \multirow[t]{2}{*}{ Total } & $\begin{array}{l}\text { Pearson } \\
\text { coefficient }\end{array}$ & $-.265 * *$ & $-0.375^{* *}$ & $-0.432 * *$ & $\overline{-}-115$ & $-0.288 * *$ & $-\overline{0.466^{* *}}$ \\
\hline & p-value & 0.008 & $<0.001$ & $<0.001$ & 0.256 & 0.004 & $<0.001$ \\
\hline
\end{tabular}

${ }^{*} \mathrm{p}<0.05, * * \mathrm{p}<0.01$

\section{Discussion}

\subsection{Sociodemographic characteristics}

There was no significant difference between the two genders in general health (physical, social, and depression) except for anxiety, and this was consistent with the research findings of Friedman and Rosenmon (15). This study showed that general health factors were more important to female employees, and this is well worth considering.

\subsection{Job satisfaction and General Health}

In this study, it was found out that there is a negative and average correlation between job satisfaction and general health of the staff; in this regard, the findings of the study were consistent with Stone Santos (16), Cho Cheng Ie (17), Strassle et al. (18), Snelgrove (19), Veisi et al. (20), and Hobbi et al. (21). Job satisfaction is a factor that can increase job efficiency and the feeling of personal satisfaction. Job satisfaction is also an indicator that shows how much are people interested in their jobs. Mental health is a multi-dimensional psychological construct with many factors that affect it. Healthy people feel happy with their own lives and job satisfaction is one of the factors that determine whether a person will be in a good emotional, intellectual, and spiritual condition; moreover, her or his mental health condition will be strengthened. It was also found that there is a negative and average correlation between job satisfaction and physical symptoms in the staff. Research findings by Lin (22) were consistent with the results of this research in this regard. It seems that mental health has a direct effect on the person's body. Indeed, feelings of healthiness and wellness, the need for additional medication, feeling weak, feeling sick, headache, and feeling of pressure on the head are all physical symptoms of general health. With the increase in job satisfaction, a person experiences a more positive feeling and therefore will have more energy physically and thus feels no need for external sources of energy as reinforcement agents. The energy source is inside the person; therefore, that person will experience less states of physical weakness, feelings of sickness, or hotness and coldness in the body. There was a negative and average correlation between job satisfaction and anxiety and sleep disorders among the staff. The results of this research were consistent with the research findings of Lu et al. (23) and Mehrabanian (5). In this regard, anxiety is often an unpleasant and vague emotional state that is associated with confusion, panic, and anxiety. These spiritual and mental states are not consistent with the mood and emotions of an individual who has job satisfaction, because having job satisfaction results in positive emotions and life satisfaction. Thus, with the increase in job satisfaction, the amount of anxiety in the individual is reduced. In this study, it was also found that there is a negative and average correlation between job satisfaction and social function; these findings of the study were consistent with research findings by Mami et al. (24) and Dehghani (25). Social dysfunctions include minor damage to continued weakness in job, social, or academic performance, and interpersonal conflict, falling behind in jobs and education, conflicts with peers or co-workers, lack of love, and finally inability to work and find a job. Sometimes the inability to function occurs in almost all areas. The signs of job satisfaction are having spirit of cooperation with colleagues, being cooperative with the organization's objectives, compatibility with the 
organizational atmosphere, and favorable relationships with clients and managers and subordinates. Therefore, it seems quite natural that, with the increase in job satisfaction, the social functioning of the individual will be satisfactory both within and outside the organization. There is also a negative or average correlation between job satisfaction and depression; the findings of the study were consistent with research findings by Dehghani (25) and Mami et al. (24) in this regard, too. Depression means confusion and decadence. According to the science of psychology, depression is the state of decrease in physical and mental activities due to sadness and sorrow, and, from the point of view of psychologists, it is defined as the state of loss and grief that is associated with feelings of intimidation, guilt, hostility, disappointment, sadness, and individual inactivity. Naturally depressed people cannot enjoy their jobs. They also cannot experience pleasant feelings because depression is a disorder that severely limits the ability of the individual. Depression also reduces the individual's ability to experience positive emotions, such as happiness, life satisfaction, and job satisfaction significantly.

\subsection{Research Limitations}

The research limitations were as follows: 1) Lack of similar research, consequently the lack of research resources for correlation; 2) Considering the research done with the personnel of one educational hospital, we only can generalize our findings to other educational hospitals.

\section{Conclusions}

In general, for better performance of an organization, a great deal of attention must be paid to employees' job satisfaction. In addition, good job status has a very significant relationship with general health. This means that the less the general health problems of the employees are, the higher their job satisfaction is. Meanwhile the relationship between the general health factors and job satisfaction showed that more attention must be paid to these factors in the work environment and among employees.

\section{Acknowledgments:}

The source of data used in this paper was a B.Sc. project of Nadia Zargani, a student at Ahvaz Jundishapur University of Medical Sciences. The research team appreciates the cooperation of all of the participants.

\section{Conflict of Interest:}

There is no conflict of interest to be declared.

\section{Authors' contributions:}

All authors contributed to this project and article equally. All authors read and approved the final manuscript.

\section{References:}

1) Nargesian E. Spiritual leadership in contemporary organizations. J Tadbir. 2008; 18(89): 29-32.

2) Sanjaghi MA, Farrahi B, ShamsAhmar M. The mediation role of organizational justice on strategic approach in human resource maintenance system and organizational commitment of the employees (case study: A public organization). Journal of Islamic Management. 2012; 19(1): 139-66.

3) Roohi G, Asayesh H, Abbasi A. The relationship job satisfaction and organizational commitment of nurses in hospitals of Golestan University of medical sciences. Payesh. 2011; 10(2): 285-92.

4) Hamid N, Dehghanzadeh $Z$. The relationship between spirituality, organizational commitment and general health with job performance of clinical nurses. Quarterly Journal of nursing management. 2012; 1(2): 20-8.

5) Mehrabanian F, Nasiripour A, Keshavarz Mohamadian S. Levels of job satisfaction in directors, managers and supervisors of various departments of public hospitals in the Gilan. Gilan Univ Med Sci J. 2005; 16(61): 65-73.

6) Miller J, Bahamon C, Lorenz L, Atkinson K. Management strategies for improving health services. Boston. 2002; 467-506.

7) World Health Organization. The world health report 2000, improving performance, Geneva.2000

8) Ahmadi SA. Study job burnout education of manager in triple amputation Esfahan. Journal research Esfahan University. 2002; 13(1): 275-84.

9) Lambert EG, BartonSM, Hogan NL. The missing link between job satisfaction and correctional staff behaviour: the issue of organizational commitment. Am J Crim Justice. 1999; 24(1): 95-116. doi: 10.1007/BF02887620.

10) ILO. Mental health in the workplace: situation analysis (preliminary report).1st edition, US ILO. Geneva, 2000. 
11) Soleimani N, AbasZadeh N, NiazAzari B. Relationship between job satisfaction and job stress in educational organization of Tehran city. Scientific Journal Management System. 2013; 3(1): 21-38.

12) Kousha A, Bagheri Sh, Janati A, JafarAbadi A, Farahbakhsh M. Comparative study of job satisfaction among health and treatment sectors' staff, East Azarbaijan. J Mil Med. 2012; 14(2): 105-12.

13) Ge C, Fu J, Chang Y, Wang L. Factors associated with job satisfaction among Chinese community health workers: a cross- sectional study. BMC Public Health. 2011; 11: 884. doi: 10.1186/1471-2458-11-884, PMID: 22111511, PMCID: PMC3248884.

14) Habib S, Shirazi MA. Job satisfaction and mental health among the employees of a General Hospital. IJPCD. 2003; 8(4): 64-73.

15) Friedman M, Rosenmon RH. An Association of specific overt behavior pattern with blood and cardio vascular findings Blood Cholesterol Level, Blood Clottinh Time, Incidence Of Arcus Senilis, And clinical coronary artery disease. JAMA. 1959; 169(12): 1286-96. doi: 10.1001/jama.1959.03000290012005.

16) St John PD, Montgomery PR. Marital status, partner satisfaction and depressive symptoms in older men and women. Can J Psychiatry. 2009; 54(7): 487-92. PMID: 19660171.

17) Cho Chang Ie. A gestalt developmental model. British gestalt journal. 2008; 17(2).

18) Strassle CG, Mckee EA, Plant DD. Mental health and job optimum as an indicator of psychological health. Journal of personality assessment. 1999; 72(2): 192-9. doi: 10.1207/S15327752JP720203

19) Snelgrove SR. Occupational stress and Job satisfaction: a comparative study of health visitors, district nurse and community psychiatric nurses. J Nurs Manag. 1998; 6: 97-104. doi: 10.1046/j.13652834.1998.00055. $\mathrm{x}$

20) Veissi M, Atef Vahid M, Rezaee M. Job stress, job satisfaction and mental health: The balancing effects of personal hardiness and social support network factors. Iranian journal of Psychiatry and Clinical Psychology.2001; 6: 70-8.

21) Hobbi MB, Moghadasi M, Hatami H, Marazabadi A, Anisi J. Relationship between job satisfaction of employees with family mental health in a military unit. Journal of military Psychology. 2011; 3(5): 57-66.

22) Lin YH, Chen CY, LU SY. Physical discomfort and psychosocial job stress among male and female operators at telecommunication call centres in Taiwan. Appl Ergon. 2009; 40(4): 561-8. doi: 10.1016/j.apergo.2008.02.024.

23) Lu K, Chang LC, Wu H. Relationship between professionals' commitment, job satisfaction and work stress in public health nurses in Taiwan. J Prof Nurs. 2007; 23(2): 110-6. doi: 10.1016/j.profnurs.2006.06.005, PMID: 17383604.

24) Mami S, Mehdian K, Davoodi Z. Investigation of depression rate in nurses working at state hospitals of the city and its associated factors scientific. Journal of Ilam University of medical sciences. 2014; $22: 51-6$.

25) Dehghani Y, Dehghani M, Mazaheri Tehrani F. Relationship among creatively, job satisfaction and mental health in female nurses. Iran Journal of nursing. 2013; 26(81): 32-43. 